\title{
Repercussões do Diagnóstico de Síndrome de Down na Perspectiva Paterna
}

\author{
Marilise Ferreira $^{1}$ \\ ${ }^{1}$ Universidade Federal de Santa Maria, RS, Brasil. \\ Luciane Najar Smeha ${ }^{3}$ \\ ${ }^{3}$ Centro Universitário Franciscano, RS, Brasil.
}

\author{
Caroline Rubin Rossato Pereira ${ }^{2}$ \\ ${ }^{2}$ Universidade Federal de Santa Maria, RS, Brasil. \\ Patrícia Paraboni ${ }^{4}$ \\ ${ }^{4}$ Universidade Federal de Santa Maria, RS, Brasil.
}

Andréia Sorensen Weber ${ }^{5}$

${ }^{5}$ Universidade Federal de Santa Maria, RS, Brasil.

\begin{abstract}
Resumo: O presente estudo objetivou conhecer como os pais lidaram com a notícia do diagnóstico de síndrome de Down à época do nascimento do filho e, posteriormente, na fase adulta desse. Para alcançá-los, nessa pesquisa de abordagem qualitativa, os pais responderam a uma entrevista de dados sociodemográficos da família eà Entrevista sobre o Lugar do Diagnóstico de Síndrome de Down na Vida do Filho. Com base na análise de conteúdo, emergiram duas categorias temáticas: o impacto do diagnóstico para os pais: "Ele (o filho) vem pela metade" e o diagnóstico na vida do filho adulto: "Teu filho é normal para ti”. Foi possível perceber que o momento do diagnóstico foi vivido como um forte impacto para os pais, associado a dúvidas e receios. Vivenciado o luto pelo filho idealizado, percebeu-se a possibilidade da construção de uma relação pai-filho de proximidade e de esperança. Além disso, os pais indicaram ter melhorado enquanto pessoas, uma vez que adquiriram aprendizados de vida a partir da convivência com as limitações do filho e demonstraram valorizar o contato com o filho na idade adulta. A partir deste estudo, destaca-se a capacidade dos pais de investirem na relação paifilho, devendo ser considerados como importantes figuras a serem incluídas nas ações de apoio à família e à pessoa com síndrome de Down.
\end{abstract}

Palavras-chave: Paternidade, Síndrome de Down, Relações pai-criança.

\section{Repercussions of Down Syndrome Diagnosis from the Paternal Perspective}

\begin{abstract}
The present study aimed to know how parents dealt with the news of the diagnosis of Down syndrome at the time of their child's birth and, later, in their adult phase. In this qualitative research, parents responded to a sociodemographic family data interview and to the Interview on the Place of Diagnosis of Down Syndrome in the Son's Life. Based on the content analysis, two thematic categories emerged: The impact of the diagnosis for parents: "The child comes in half" and the diagnosis in the life of the grown up child: "Your grown up child is normal for you". It was possible to perceive that the moment of the diagnosis was lived as a strong impact for the parents, associated with doubts and fears. After experiencing the mourning for the idealized child, the possibility of building a parents-child relationship of closeness and hope emerged. In addition, the parents indicated that they had improved as people, since they acquired lifelong learning from the coexistence with the limitations of the child and demonstrated to value the contact with the grown up child in the adult age. From this study, we highlight the parents' ability to invest in the parents-child relationship, and argue that they should be considered as important figures to be included in actions to support the family and the person with Down syndrome.
\end{abstract}

Keywords: Paternity, Down's syndrome, Parent-son relationships. 


\title{
Repercusiones del Diagnóstico del Síndrome de Down desde la Perspectiva Paterna
}

\begin{abstract}
Resumen: El presente estudio tuvo como objetivo conocer cómo los padres trataron las noticias del diagnóstico de síndrome de Down en el momento del nacimiento del niño y, más tarde, em su fase adulta. Para llegar a ellos, en esta investigación cualitativa, los padres respondieron a una entrevista sociodemográfica de datos familiares y a la Entrevista sobre el Lugar del Diagnóstico del Síndrome de Down en la Vida del Hijo. Basado en el análisis de contenido, surgieron dos categorías temáticas: El impacto del diagnóstico para los padres: “Él (el hijo) viene por la mitad" y El diagnóstico en la vida del hijo adulto: “Tu hijo es normal para ti”. Se pudo percibir que el momento del diagnóstico fue vivido como un fuerte impacto para los padres, asociado con dudas y temores. Experimentado el duelo por el hijo idealizado, se percibió la posibilidad de construir una relación padre-hijo de cercanía y esperanza. Además, los padres indicaron que habían mejorado como personas, ya que adquirieron aprendizaje permanente de la coexistencia con las limitaciones del hijo y demostraron valorar el contacto con el hijo en la edad adulta. A partir de este estudio, se destaca la capacidad de los padres para invertir en la relación padre-hijo, y deben considerarse como figuras importantes para ser incluidas en acciones de apoyo a la familia y la persona con síndrome de Down.
\end{abstract}

Palabras clave: Paternidad, Síndrome de Down, Relaciones entre padres e hijos.

\section{Introdução}

No Brasil, a cada 600 a 800 nascimentos, nasce uma criança com síndrome de Down, seja qual for a etnia, gênero ou classe social (Ministério da Saúde, 2013). Em termos diagnósticos, a síndrome de Down caracteriza-se por uma alteração genética, devido à existência de um cromossomo a mais no par cromossômico 21, recebendo o nome de Trissomia do 21 (Castro, \& Pimentel, 2009). Dentre as consequências desta síndrome estão, modificações fisiológicas, cognitivas e motoras (Espigares, 2012). Segundo Cunningham (2008), além de uma condição genética, a síndrome de Down se apresenta de forma complexa, envolvendo uma variedade de alterações e especificidades em cada sujeito. O fenótipo dessa síndrome caracteriza-se, por exemplo, por pregas palpebrais oblíquas para cima, epicanto, base nasal plana, face aplanada, protusão lingual, pé plano, hipotonia, entre outras características. Contudo, nem todas as características necessitam estar presentes para a realização do diagnóstico clínico. Além disso, podem estar associados à síndrome: cardiopatias congênitas, alterações auditivas, endocrinológicas, do aparelho locomotor, neurológicas e hematológicas (Ministério da Saúde, 2013).

A deficiência intelectual também se constitui em uma característica importante da síndrome de Down
(Alonso, 2011). Em decorrência do comprometimento intelectual, estes sujeitos apresentam uma necessidade maior de tempo para assimilar e compreender as mensagens recebidas nas interações sociais (Espigares, 2012). Portanto, pode-se pensar que estas pessoas apresentam algumas particularidades em seu modo de se relacionar socialmente e que características da síndrome podem trazer implicações para seus relacionamentos no contexto familiar. Além disso, a rotina de tratamento devido às complicações médicas e mesmo as intervenções e terapêuticas focadas nas limitações de desenvolvimento associadas à síndrome de Down repercutem nas relações familiares, dentre elas, a construída entre pai e filho.

Embora o nascimento de uma criança com necessidades especiais ocasione modificações e exija adaptações no grupo familiar como um todo, a literatura tende a apresentar a mãe como aquela que sofre o principal impacto diante do diagnóstico do filho (Matos, Andrade, Mello, \& Sales, 2006). No estudo de Sunelaitis, Arruda e Marcom (2007), do qual participaram três mães paranaenses de bebês com síndrome de Down, as mães indicaram não ser fácil receber a notícia do diagnóstico de uma alteração genética complexa como a síndrome de Down. Contudo, pode-se pensar a partir disso, que o pai também sofre de forma 
direta esse impacto, embora a maneira de manifestação do sofrimento seja diferente e menos explícita que a da mãe. Nesse sentido, no estudo de Albuquerque, Pereira, Fonseca e Canavarro (2012) com pais e mães de crianças com um diagnóstico de Anomalia Congênita não houve diferenças entre os genitores na percepção de sobrecarga relacionada ao diagnóstico.

Diante do diagnóstico do filho, Cunha, Blascovi-Assis e Fiamenghi Junior (2010) identificaram que tanto as mães quanto os pais vivenciaram sentimentos como o de desorientação, choque, perda da idealização sobre o filho e ansiedade diante do futuro. Matos et al. (2006) indicaram reações semelhantes, envolvendo choque, desapontamento, perda do filho ideal e falta de segurança ao lidar com a nova realidade.

Na pesquisa de Henn e Piccinini (2010), ao investigarem o envolvimento e a experiência da paternidade de seis pais de filhos com síndrome de Down da cidade de Porto Alegre, a descoberta diagnóstica também foi identificada como um momento que fez emergir sentimentos intensos nos pais, como choque, lamentação, tristeza, além do nervosismo e preocupações no que diz respeito ao futuro desse filho. Sentimentos como esses haviam sido apontados pelas mães do estudo de Sunelaitis et al. (2007), que descreveram reações de decepção e revolta diante do diagnóstico e a presença de tensão, angústia e estresse após o nascimento do filho.

Ainda com relação ao diagnóstico do filho, em um estudo com 12 pais da cidade do Rio de Janeiro com filhos identificados com uma malformação congênita, identificou-se que todos os pais apresentaram sentimentos como tristeza, sendo que 91\% dos pais apresentaram sinais mínimos de depressão (Silva, Girão, \& Cunha, 2016). Os sintomas depressivos paternos poderiam estar associados ao estresse relacionado ao medo do homem em falhar nas tarefas de provedor, apoiador emocional e parceiro romântico (Falceto, Fernandes, \& Kerber, 2012), ou seja, às pressões associadas ao desempenho de um papel paterno ainda fortemente vinculado a estereótipos de gênero, podendo se agravar frente ao diagnóstico de síndrome de Down do filho (Iaconelli, 2011).

O momento do diagnóstico, invariavelmente, estará atravessado por reações emocionais de maior ou menor intensidade. Tais emoções podem ser, inclusive, comparáveis ao luto vivido pelos pais que perdem um bebê durante a gestação (Cunningham,
2008; Sunelaitis et al., 2007; Travassos-Rodriguez, 2007). Assim, ter perdido o bebê ideal, se deparado com a chegada do bebê real, além da forma como foi transmitida a notícia, a intervenção dos profissionais, o contato entre eles e o luto dos familiares serão conteúdos fundamentais para a constituição do bebê como um sujeito na família (Gutfreind, 2010). Tal processo de luto também é referido na pesquisa norte-americana de Bentley, Zvonkovic, McCarty e Springer (2015), em que os pais de crianças com síndrome de Down demonstraram a ambiguidade de amar o filho que tiveram, mas também, paralelamente, lamentarem a vida que sonhavam em ter com um filho sem deficiência.

Nos momentos posteriores ao diagnóstico, espera-se, então, que os pais passem por algumas etapas de adaptação (Klaus, Kennell, \& Klaus, 2000), ou fases de luto (Fainblum, 2008) ou, ainda, estágios de reorganização (Cunha et al., 2010). Destaca-se, então, que se trata de um processo gradual de elaboração e adaptação à nova realidade, de modo que as idealizações e expectativas quanto ao filho possam ser ressignificadas, adquirindo um caráter de elaboração da nova condição no sentido de viabilizar a aceitação do diagnóstico do filho. Quando isso não acontece, pode indicar que o pai encontra dificuldades em renunciar à imagem do filho ideal. Tal contexto traz consigo o risco de que se subtraia ao bebê real uma posição de investimento afetivo, podendo dificultar o estabelecimento do vínculo pai-filho (Fainblum, 2008).

Segundo Henn e Piccinini (2010) os pais participantes de seu estudo mencionaram que já durante os primeiros dias de relação com o filho foi possível começar a aceitar o fato de serem pais de uma criança com síndrome de Down. No que tange ao envolvimento posterior do pai com os filhos com síndrome de Down, os autores identificaram variadas maneiras de participação, como ir a consultas médicas, alimentar, vestir, arrumar o filho e brincar com ele.

Contudo, tal envolvimento paterno com os cuidados com os filhos não tem sido consenso na literatura sobre a relação pai-filho com deficiência. Em uma pesquisa realizada com famílias brasileiras de crianças com deficiência intelectual, sendo a maioria com diagnóstico de síndrome de Down e nível socioeconômico baixo, Souza e Fiamenghi (2011) destacaram que os pais desempenhavam seu papel a partir de uma perspectiva tradicional de gênero, com papéis fixos e estereotipados, destinados aos pais e às mães. 
Nesse caso, o cuidado das tarefas domésticas e dos filhos era assumido pelos pais apenas em situações de impedimento da mãe. Além disso, o estudo revelou pouco contato do pai com as instituições especializadas que atendiam a criança e, em decorrência, uma compreensão restrita das dificuldades e limitações das crianças.

Conforme os filhos avançam em idade, algumas especificidades e desafios se apresentam na relação parental. Quando o filho chega à idade adulta, pais e mães ainda possuem um importante papel a desempenhar em suas vidas. No entanto, a literatura na área da Psicologia, frequentemente, apresenta estudos sobre o tema focados na fase da infância e/ou adolescência (Bastos, \& Deslandes, 2009; Bentley et al., 2015; Henn, \& Piccinini, 2010), sem que haja um investimento na investigação da relação pai e filho com síndrome de Down na fase adulta.

Houve um tempo em que poucas pessoas com síndrome de Down chegavam à fase adulta e, geralmente, viviam em instituições que os isolavam da comunidade. Atualmente, o convívio e a interação com o sistema familiar e outros contextos sociais ainda podem ser restritos, mas, algumas possibilidades de efetiva participação social influenciaram positivamente em sua maior visibilidade. Assim, hoje, o adulto com essa síndrome passa a ser mais perceptível (Casarin, 2003). No âmbito legal, em 2015, entrou em vigor a Lei ${ }^{\circ}$ 13.146, de Inclusão da Pessoa com Deficiência (Estatuto da Pessoa com Deficiência), promovendo os direitos e a liberdade das pessoas com deficiência com o objetivo de dar-lhes garantia de cidadania e inclusão social. Tal legislação garante condições de acesso à saúde e à educação e, ainda, estabelece punições para atitudes discriminatórias (Anônimo, 2016).

Almeida (2013) salientou que o desenvolvimento de indivíduos que possuem a síndrome de Down sofre influência da qualidade do cuidado, educação e experiência que lhe são oferecidos. O dia a dia, independentemente da idade que o filho com síndrome de Down possua, encontra-se permeado pelos recursos que lhe estão disponíveis e pela atitude das pessoas que vivem com ele, com quem convive na comunidade e das pessoas que o sustentam e/ou ensinam.

É indiscutível a importância do pai na vida dos filhos, sendo sua presença atualmente compreendida como um fator de proteção ao desenvolvimento dos filhos (Bossardi, \& Vieira, 2010; Cia, Williams, \& Aiello,
2005; Bueno, \& Vieira, 2014). Todavia, os pais, historicamente, não têm recebido o mesmo destaque que as mães nas investigações e produções em Psicologia, no que diz respeito a esse tema. Segundo Goetz e Vieira (2013), na Psicologia há um menor investimento de estudos sobre a contribuição do pai para o desenvolvimento dos filhos, considerando-se a mãe como a protagonista nos seus cuidados e como aquela apta a informar sobre as relações familiares. Ao se considerar o papel paterno em um contexto mais específico, como é o caso de um filho com síndrome de Down, a escassez de estudos é ainda mais marcante. Além disso, as percepções de pais sobre os filhos com síndrome de Down em idade adulta ainda são pouco conhecidas pela comunidade científica.

A partir do exposto, destaca-se a relevância de se investigar a visão que os pais possuem sobre seus filhos com síndrome de Down e como lidam com o diagnóstico do filho, tanto no momento inicial quanto tardiamente em sua vida. Assim, neste estudo, buscou-se, a partir de um olhar focado no pai, conhecer como os pais lidaram com a notícia do diagnóstico de síndrome de Down à época do nascimento do filho e, posteriormente, na sua fase adulta.

\section{Método}

\section{Delineamento e Procedimentos}

Esse estudo possui natureza qualitativa e caráter exploratório-descritivo. Conforme Minayo (2014) a pesquisa qualitativa trabalha com o universo de significados, motivos, crenças e atitudes dos sujeitos. Sabadini, Sampaio e Koller (2009) complementaram afirmando que a abordagem qualitativa busca explicar o "como" e o "porquê" dos fenômenos.

No que tange aos procedimentos adotados no estudo, posteriormente à obtenção das autorizações institucionais, a pesquisa foi submetida ao Comitê de Ética em Pesquisa com Seres Humanos da Universidade Federal de Santa Maria (UFSM). Depois de aprovada (CAAE 51624415.0.0000.5346), os pais, que haviam sido indicados pela associação/instituição ou por indicação, foram contatados via telefone a fim de serem convidados a participarem do estudo. Com aqueles pais que demonstraram interesse, foi agendado um encontro presencial, momento em que receberam explicações detalhadas acerca da pesquisa, e foram informados sobre seus aspectos 
éticos, sendo solicitados a assinarem o Termo de Consentimento Livre e Esclarecido (TCLE), autorizando sua participação no estudo. Uma vez assinado o TCLE, os pais respondem à solicitação de informações sobre os dados sociodemográficos da família, assim como a perguntas sobre o diagnóstico de síndrome de Down na vida do filho. Estas entrevistas ocorreram em uma das salas das instituições, tiveram duração média de setenta minutos e foram gravadas em áudio. Posteriormente, as entrevistas foram transcritas na íntegra e, com base em sua análise, estabeleceram-se as categorias temáticas que compõem os resultados deste estudo.

\section{Participantes}

Participaram do estudo quatro pais de filhos adultos com síndrome de Down, que residiam com seus filhos. Os pais possuíam idades entre 52 e 73 anos e os filhos tinham idades entre 27 e 37 anos, sendo três homens e uma mulher. A Tabela contém a caracterização dos participantes.

No momento da coleta de dados os participantes residiam em um município na região central do RS. Três pais eram casados, residiam com as mães dos filhos e um pai (P4) era viúvo e vivia com uma nova companheira/esposa. Todos os filhos dos participantes possuíam irmãos, sendo que apenas no caso quatro esses residiam com a família, sendo uma irmã consanguínea e uma irmã por parte da madrasta.

Os pais foram acessados por meio de duas instituições e por indicação. Uma das instituições referia-se a uma associação de pais e amigos das pessoas com síndrome de Down e a outra era uma escola que presta serviços, em diferentes áreas, às pessoas com deficiência e suas famílias. Ambas estavam localizadas na cidade de moradia dos participantes.

\section{Instrumentos}

Os pais responderam a um questionário com dados sociodemográficos da família e à Entrevista sobre o diagnóstico de síndrome de Down. A entrevista, elaborada pelas autoras do estudo, correspondeu à modalidade semiestruturada, sendo composta por perguntas abertas e fechadas, proporcionando maior possibilidade de aprofundar determinados temas sem se prender à indagação formulada pelo entrevistador (Minayo, 2014). A entrevista baseou-se em um roteiro contendo as seguintes temáticas: 0 processo diagnóstico do filho, a construção da relação pai-filho com o avançar da idade, características da relação pai-filho ao longo do desenvolvimento do filho e singularidades da relação diante da deficiência.

\section{Análise dos dados}

Utilizou-se como estratégia a análise de conteúdo (Bardin, 1977/2010) que, segundo a autora, é composta por três fases: pré-análise; exploração do material; tratamento dos resultados, inferência e interpretação. A fase de pré-análise envolve a organização do material, em que se intuem questionamentos, tornando operacionais e sistematizadas as ideias iniciais. Na fase da exploração do material, decompõe-se o texto, codificando os fragmentos encontrados. $\mathrm{Na}$ última etapa, realiza-se o tratamento dos dados encontrados, interpretando-os e lançando inferências a partir deles (Bardin, 1977/2010).

Neste estudo, as entrevistas transcritas foram lidas exaustivamente a fim de identificar os focos de sentido atribuídos pelos participantes ao diagnóstico do filho com síndrome de Down, que deram, então, origem às categorias temáticas. As categorias derivadas da análise tiveram, então, como unidade de análise os temas identificados, tendo sido construídas $a$

Tabela

Caracterização dos participantes.

\begin{tabular}{lcccccc}
\hline $\begin{array}{l}\text { Número } \\
\text { do caso }\end{array}$ & $\begin{array}{c}\text { Idade } \\
\text { do pai }\end{array}$ & $\begin{array}{c}\text { Ocupação } \\
\text { do pai }\end{array}$ & $\begin{array}{c}\text { Idade } \\
\text { do filho }\end{array}$ & $\begin{array}{c}\text { Sexo } \\
\text { do filho }\end{array}$ & $\begin{array}{c}\text { Com quem mais } \\
\text { residiam }\end{array}$ & $\begin{array}{c}\text { Irmãos que } \\
\text { não residiam } \\
\text { com a família }\end{array}$ \\
\hline 1 & 59 & Motorista & 27 & Masculino & Mãe & 1 \\
2 & 72 & $\begin{array}{c}\text { Aposentado } \\
\text { Aposentado }\end{array}$ & 31 & Masculino & Mãe e avó materna & 1 \\
3 & 73 & $\begin{array}{c}\text { Autônomo } \\
\text { (pintor) }\end{array}$ & 30 & Feminino & Madrasta e 2 irmãs & 2 \\
4 & 52 & & & & Masculino & Mãe \\
\hline
\end{tabular}


posteriori, ou seja, com base no material coletado. De acordo com Laville e Dionne (1999) o recorte de conteúdo em temas se constrói através de fragmentos, sendo que cada um deles relaciona-se a uma ideia. Conforme as autoras, com esta estratégia é possível aproximar o pesquisador do sentido do conteúdo, pois se depara com o dever de constituir suas unidades por meio da compreensão dos dados coletados.

\section{Resultados e discussão}

\section{O impacto do diagnóstico para os pais: "Ele (o filho) vem pela metade"}

No que se refere ao diagnóstico de síndrome de Down do filho, os pais revelaram terem sofrido um forte impacto à época da gestação e nascimento do filho. Para os pais, o diagnóstico esteve associado à perda de um filho idealizado e necessidade de olhar para um "novo filho": "O impacto foi violento pra gente. A gente imaginava ele normal. Nós olhávamos pra ele, nós chorávamos. Nós não imaginávamos o que que poderia ser. Porque que tem um filho, ele vem pela metade, mas tu não quer perder. Então, nós ficamos totalmente derrubados" (P2); “Ah, não é agradável, né. A gente fica chateado. A gente sente. É que a gente espera uma criança normal e tal, como qualquer um. E aí recebe, não é fácil” (P3); "Que daí o médico me falou e foi muito complicado aceitar. Não aceitar, aceitar ela como filha eu aceitei, só que a gente não tinha informação nenhuma a respeito do que que era a síndrome de Down" (P4).

Tais relatos estão de acordo com a literatura que indica o momento do diagnóstico como um período crítico, marcado pela presença de sentimentos como de choque, desorientação, lamentação, tristeza e/ou preocupações quanto ao futuro do filho (Cunha et al., 2010; Henn \& Piccinini, 2010; Pereira-Silva \& Almeida, 2014). Além disso, os pais também precisam lidar com a dificuldade de aceitação dessa criança que nasceu diferente do que esperavam (Ministério da Saúde, 2013), levando à perda da imagem idealizada que havia sido construída para o filho (Cunha et al., 2010; Matos et al., 2006). Independentemente do momento em que o diagnóstico foi comunicado, durante a gestação ou após o nascimento do filho, as angústias, o luto e a preocupação frente à notícia são frequentes (Cunha et al., 2010).

Quando nasce um filho com síndrome de Down, sentimentos de dúvida, incerteza e insegurança são também comuns, seja em razão da saúde do filho, seja diante de seu potencial em termos de desenvolvimento, independência no futuro e qualidade de vida (Ministério da Saúde, 2013). O sentimento de dúvida e receio apresentado pelos pais pode estar relacionado à falta de conhecimento sobre as necessidades de um filho com síndrome de Down, envolvendo a saúde física, o processo de socialização, o desenvolvimento global do filho. Segundo pesquisa de Cunha et al. (2010), o sofrimento dos pais em parte era devido ao fato de não possuírem informações suficientes sobre a condição clínica do filho.

Embora haja muitas dificuldades no momento da descoberta do diagnóstico, alguns pais referiram uma reação de menor impacto diante do diagnóstico do filho. Em outras palavras, de certa aceitação e naturalidade ao lidar com a notícia: "Não é uma notícia muito... mas a gente tem que aceitar. É filho, a gente quer filho, então, como ele vem, a gente tem que aceitar" (P3); "Ah, eu fiquei emocionado (com o diagnóstico). Mas não foi uma coisa assustadora, assim. Eu sempre aceitei com a maior naturalidade [...]. É, foi a confirmação só pra deixar claro. Mas o resto a gente já tinha aceitado numa boa, não tinha problema” (P1).

Conforme Pereira-Silva e Almeida (2014), além dos sentimentos de choque, negação, rejeição, também vai se apresentando a aceitação e a busca de informação sobre a síndrome. Tal postura pode estar atrelada ao fato de os pais já identificarem algo de "diferente" no filho, mesmo antes da confirmação do diagnóstico médico: "Desde criancinha, que ele nasceu no hospital a gente já sabia que ele ia ser Down" (P3); "A fisionomia dele, o rostinho dele era bem diferente. Aquilo já estava nos mostrando que alguma coisa errada ele tinha. Opa, 'O que que é doutor?'. Nós tínhamos uma coisa, assim, que não tava certo, que ele era diferente" (P2).

Os pais eram perceptivos ao ponto de terem consciência de que havia características singulares em seu filho, apesar de não terem uma confirmação médica ainda. Esse dado se contrapõe, de certa forma, com o da pesquisa de Matos et al. (2006), segundo a qual as participantes demonstraram negação frente às alterações que diziam respeito à síndrome. No presente estudo, parece que os pais usaram essas características para buscar prepararem-se para a notícia do diagnóstico, que veio como a confirmação de suas suspeitas: "Aí foi a confirmação quando ele fez o cariótipo" (P1); "A confirmação veio três meses depois, 
quando nós fomos fazer o cariótipo, aquele exame que diz propriamente que tem a síndrome" (P3); "Na época não existia exame pra saber se a criança tinha ou não, a não ser particular [...]. E só fomos saber que era síndrome de Down na hora que ela nasceu" (P4).

Um aspecto que também pode interferir nos sentimentos, diante de um diagnóstico de síndrome de Down de um filho, envolve a maneira como os profissionais não só transmitem a notícia aos pais, mas também, como orientam e/ou acompanham o caso. Ainda sobre o caso 3, o pai relatou que no momento do diagnóstico sentiu falta de informação por parte da equipe de saúde, considerando que à época do nascimento do filho não se conhecia tanto sobre a síndrome de Down como na atualidade.

Ninguém explicava pra nós o que era. Hoje não, uma criança, antes de nascer, os pais já sabem. Então, foi muito complicado pra gente. Tu leva um soco na boca do estômago. Ele só disse: "A tua filha é doente. A tua filha tem isso e isso", mas virou as costas e foi embora. Uma enfermeira, ninguém, ninguém me explicou o que que era. Depois que eu fui ver ela (filha): "Mas o que que ela tem de anormal? De doente?". Levei tempo pra descobrir. Daí tu vai descobrir, é bem diferente. A doença dela é um atraso (P4).

Essa falta de conhecimento, de informação e mesmo de apoio técnico pode interferir nas expectativas criadas acerca do filho e mesmo na busca por tratamentos para os mesmos.

Trinta anos atrás, os síndromes de Down eram quase uma aberração. Aí começaram "Ah, porque ela tem poucos anos de vida”. Ta aí ela com trinta anos, super bem, mais sã que nós. Só que na época foi muito triste. Nós fomos começar a achar isso aí (SD), ela tinha acho que dez anos. Imagina, dez anos de atraso pra ela. Nós não tínhamos informação. Alguém tivesse me orientado, a gente teria procurado recurso. Eu não sabia de ninguém que tinha quase, porque, há trinta anos, tu via pouco e os que tinham estavam escondidos (P4).

No estudo de Pereira-Silva e Dessen (2003), com seis famílias compostas por mãe, pai e criança com síndrome de Down, a forma como os médicos lhes apresentaram o diagnóstico do filho não lhes pareceu apropriada. Assim, por não estarem preparados para tal notícia e não possuírem conhecimento suficiente sobre ela, isso deu lugar ao desenvolvimento de fantasias sobre a síndrome. As participantes do estudo de Sunelaitis et al. (2007) também mencionaram que sabiam pouco sobre ela, mesmo tendo convivido já algum tempo com esse filho.

A ampliação do conhecimento e sua divulgação nas mídias digitais contribuiu para o aumento da expectativa de vida das pessoas com síndrome de Down a partir da segunda metade do século XX. Os avanços na área da saúde e a construção de programas do governo para orientar os cuidados na saúde, a inclusão para favorecer o acesso à educação no ensino, visando à inserção profissional, independência e também qualidade de vida dos sujeitos, foram alguns dos avanços (Ministério da Saúde, 2013).

Conforme Glat e Duque (2003) não se pode afirmar que estes pais não passaram por episódios de angústia e, até mesmo desespero, frente ao diagnóstico dos filhos. No entanto, gradualmente, a insegurança pode ser superada e uma maior conscientização dos pais acerca da situação vai sendo construída. Assim, é fundamental que os pais tentem lidar e superar os desafios diários, já que é enfrentando a realidade e não se afastando dela, que construirão uma relação de qualidade com esse filho.

\section{O diagnóstico na vida do filho adulto: "Teu filho é normal para ti”}

De um modo geral, percebeu-se que, com o passar do tempo, os pais conseguiram elaborar a nova situação, sendo que a forma como receberam o diagnóstico se tornou um fator fundamental nesse processo. As falas apontaram para a sensação de que o tempo auxiliou esses pais a vivenciarem de forma positiva a situação, aprendendo a lidar com o filho e com seu diagnóstico: "Aí a gente explicava pras pessoas, a gente ficava meio assim. Mas agora não, agora a gente tá mais natural. Se precisa falar alguma coisa, a gente não tá nem aí” (P1); "Então, só o tempo foi nos colocando direitinho nos lugares e nós procurando fazer tudo como tinha que fazer. E hoje tô aqui" (P2); "Com o tempo, a gente vai administrando. E vai achando e vai superando. E, cada dia que passa, fica mais legal" (P3).

Notou-se um grande envolvimento paterno no cuidado com o filho desde pequeno. Este cuidado 
se expressou, também, na busca de informações que, como visto, não estavam disponíveis, já que, como na pesquisa de Cunha et al. (2010) os casais obtiveram pouca ou nenhuma informação sobre a síndrome, quando foram informados sobre o diagnóstico do filho: "Naquela época, a gente não tinha experiência" (P3).

No início, qualquer coisinha, a gente queria saber alguma coisa sobre Down, sempre tava tentando descobrir alguma coisa. A M. (esposa) estudava muito, lia muito, e eu escutava, às vezes lia um pouco. O sentimento era muito aflorado, porque eram muito cobradas as coisas. Antigamente, há 20 e poucos anos, não era que nem agora, muito liberal (P1).

A gente levou muitos anos pra começar a procurar recurso, fonoaudióloga, um acompanhamento pra ela. Quando viemos pra Y. (cidade de residência atual), que daí a gente começou a ter mais recurso. Só que daí já tinha passado aquele tempo do aprendizado. Ela começou a caminhar com cinco anos. Imagina (P4).

O potencial a ser desenvolvido parece ser um desafio diário (Ministério da Saúde, 2013). Frente ao diagnóstico de síndrome de Down do filho, segundo pesquisa de Henn e Piccinini (2010), há o confronto com uma realidade com a qual os pais não estavam acostumados, precisando, assim, irem em busca de informações em revistas e livros, a fim de estudarem a respeito, além de apontarem a importância da "estimulação" para o desenvolvimento desses filhos. Alguns pais da pesquisa de Glat e Duque (2003), inclusive, mudaram seus horários e rotina para possibilitarem maior auxílio aos filhos, participando ativamente de suas vidas. Apesar da possível exaustão devido ao envolvimento com o tratamento, a educação e a estimulação da independência do filho, tais atividades também eram fonte de satisfação para os pais.

Percebeu-se, então, a capacidade dos pais de reconhecerem seu filho e investirem nesta relação desde muito cedo. Os pais indicaram vincular-se e dedicar-se intensamente ao filho, atendendo às suas necessidades e adaptando-se a elas: "Eu que dei banho primeiro nele, em casa [...]. Nós passamos dois meses cuidando dele, intensamente. Não descuidamos. Dava mamá numa coisinha pequeni- ninha, na boca dele. Cada vez que aumentava 100g, pra nós era uma vitória. E aí ele foi crescendo" (P1); "Ser uma criança com síndrome de Down, mas que andasse, caminhasse. Então, daquele dia em diante, nunca mais nós paramos. [...] Qualquer coisinha, via ele diferente, a gente já corria no médico. E nunca mais paramos" (P2).

Na literatura é consenso o fato de existir, hoje, um pai mais participativo na vida dos filhos e nos seus cuidados (Amiralian, 2014; Balancho, 2004; Féres-Carneiro, Zivianu, Magalhães, \& Ponciano, 2013; Staudt, \&Wagner, 2008). Segundo Pereira (2003) esse cenário responde às mudanças no lugar ocupado pela mulher na sociedade, iniciadas na década de 1960 e intensificando-se nas últimas décadas do século passado. A partir daí, os homens passaram a vivenciar uma maior participação efetiva dentro da família, não se limitando a representantes da autoridade ou do sustento financeiro. No caso específico deste estudo, chama atenção o fato de os pais, que tiveram seus filhos já há três décadas, apresentarem uma postura tão envolvida e dedicada ao filho, o que pode ter sido intensificada pela presença da síndrome de Down.

Acredita-se que a demanda de atenção e cuidados com um filho com síndrome de Down podem ser maiores que em outros contextos que não envolvem deficiências. Isso poderia explicar um maior envolvimento e proximidade do pai com o filho. Portanto, nesse contexto, pode ocorrer de a condição do filho englobar, na sua relação com o pai, maior participação e comprometimento pelas demandas existentes. O estudo de Darke e Goldberg (1994), que investigou possíveis repercussões da doença crônica na relação pai-filho, considerando crianças saudáveis, filhos com fibrose cística e filhos com doença cardíaca congênita, evidenciou que no grupo de fibrose os pais que apresentavam mais tempo envolvidos com o tratamento do filho se relacionavam de forma mais comprometida com os mesmos na interação no laboratório de pesquisa. Da mesma forma, o presente estudo identificou que a convivência diária entre pai e filho foi importante para o vínculo afetivo, de modo que os pais pareciam possuir papel central na vida dos filhos.

Neste mesmo sentido, Ethier (1999) desenvolveu um estudo no Canadá com seis pais e mães de crianças com necessidades especiais e seis pais e mães de crianças com desenvolvimento típico. Foi possível identificar que os pais e mães de crianças com neces- 
sidades especiais, embora tivessem escolhas mais restritas quanto às atividades a serem desenvolvidas com os filhos, mostraram-se mais envolvidos com estes.

Considerando-se o modo como o diagnóstico do filho foi vivido pelos pais com o avançar da idade do filho, chama atenção que, ao descreverem sua percepção do filho no momento atual, usaram o termo "normal" para descrever o filho: "Ele tem essa síndrome de Down, mas ele, pra mim, não tem nada” (P2); “Não, pelo contrário, eu acho normalíssimo e trato ele como normal. Nunca vem à baia ${ }^{1}$ essa situação da síndrome. Não interfere de maneira alguma” (P3); “Às vezes, tu quer que teu filho seja normal. Teu filho é normal pra ti. Pros outros não importa" (P4).

Percebe-se que, partindo de um momento inicial de diagnóstico, em que a diferença apresentada pelo filho foi sentida como muito marcante, com o passar do tempo e o estreitamento dos laços afetivos, a síndrome de Down deixa de ser sentida como o foco da relação com o filho. Esta forma de ver o filho, não parece indicar uma negação de sua deficiência, mas sim que a criança passa a ser considerada como central, a despeito da síndrome. Ainda, pensa-se que esses pais procuram proteger o filho de qualquer preconceito ou discriminação. Portanto, cogitar em "diferença" ou "singularidade" deste poderia, em alguma medida, ser tomado como uma não aceitação do filho em si. Pode-se supor que o que os pais desejam expressar seja que não percebem seus filhos como "falhos", "incompletos", aceitando-os com suas características especiais.

Além de indicar não ver o filho como diferente em função da síndrome de Down, pode-se perceber que a presença da síndrome singularizou a relação pai-filho, no sentido de uma grande dedicação diante das necessidades apresentadas e uma consequente gratificação envolvida.

Não sei, se por felicidade maior, Deus me deu este filho. Se ele fosse um filho normal, pra mim seria tudo no mundo. Mas como ele não é normal e eu tenho esta graça de ter este filho, ele é mais tudo no mundo pra mim. Parece que a gente sabe do amor que a gente tem por ele e a necessidade que ele tem. A gente sabe que ele vai ser um filho que vai precisar de nós o resto da vida. A felicidade é maior. Eu não queria que ele fosse normal. Eu não trocaria hoje, porque nós nos apegamos tanto. Nos apegamos tanto a ele, tanto o amor que nós temos pela deficiência dele, por ele ser o que ele é (P2).

Conforme os pais, as evoluções que estes filhos apresentavam diante de suas dificuldades proporcionam sentimentos de ânimo no pai. Com isso, diante das limitações associadas à deficiência, esses avanços eram ainda mais valorizados: "É bom. É o que dá conforto pra gente, que anima. É ver que ele progride, que responde a algumas expectativas, de evolução dele" (P3); "A singularidade seria a capacidade dele transmitir que ele gosta da gente também, que ele sabe que é bem-aceito entre todo mundo, que ninguém discrimina ele. Então, ele se sente normal na frente de todo mundo. Ele nunca se sentiu discriminado" (P1).

Além disso, os pais indicaram que melhoraram enquanto pessoas, uma vez que adquiriram aprendizados de vida a partir da convivência com as limitações do filho, valorizando o contato prolongado com o filho, mesmo na idade adulta. Percebe-se a possibilidade de, a partir de uma situação inicial difícil, extrair ensinamentos e visualizar vantagens: "Ah, ele ensinou muito pra mim. Ver a vida de um ângulo diferente. Isso é o forte da coisa. A aceitação da situação dele serve pra gente, pro crescimento da gente. A gente tem que se dobrar, tem que se esforçar. Isso tudo ele ensina pra gente, mais que os normais" (P3).

Com essa idade, se ela não tivesse essa diferença de gene, tu acha que ela taria aqui hoje? Eu acho que não. São coisas que só Deus explica. A gente não sabe. As outras duas minhas (filhas) tão em X. [cidade de outro estado] e tão cheia de problema, e eu com ela não tenho problema nenhum. Só agradeço a Deus (P4).

Esta visão positiva acerca do diagnóstico do filho na vida dos pais havia sido identificada por Pereira-Silva e Almeida (2014). Em um estudo com pais e mães com filhos com deficiência da cidade de Brasília, posteriormente ao choque diante do diagnóstico, os pais afirmaram conseguir se adaptar ao contexto, apresentando satisfações e esperanças em relação ao desenvolvimento do filho.

\footnotetext{
${ }^{1}$ Expressão regionalista com significado similar à "vem à tona”.
} 
Com o passar do tempo, os desafios podem se tornar mais complexos, demandando desses pais, e da família, novas ações a cada etapa do desenvolvimento. Contudo, estes obstáculos podem ser enfrentados e percebidos de forma a valorizar os aspectos positivos e os potenciais dos filhos. Assim como neste estudo, na pesquisa de Glat e Duque (2003) os pais procuraram dar destaque às características positivas dos filhos e ao fato de que estes ainda tinham a possibilidade de desenvolver suas habilidades. A valorização de seu potencial e subjetividade mostrava o que de melhor podiam proporcionar aos filhos, mesmo percebendo as dificuldades existentes.

Assim, por mais que o momento do diagnóstico, quando do nascimento do filho, tenha se configurado como uma experiência difícil para os pais, isso não os impediu de investir no filho e na sua relação com o mesmo, ao longo do seu desenvolvimento e do seu crescimento. Com o passar do tempo, a experiência de luto pareceu dar lugar à construção de uma relação pai-filho baseada no afeto, na proximidade e na esperança, que perdurava na fase adulta do filho.

\section{Considerações finais}

As dificuldades iniciais são marcantes, os participantes do estudo relataram o sofrimento, tristeza e receio diante do diagnóstico e das necessidades do filho com deficiência. Já na fase adulta dos filhos, nas lembranças do momento do diagnóstico, há uma predominância nos relatos quanto à falta de empatia da equipe de saúde, poucas informações sobre a síndrome e uma sensação de desamparo. Este estudo evidenciou que quando os pais recebem a notícia com muita ênfase nos aspectos negativos da criança, eles podem ter mais dificuldades para processar a informação e reorganizar a vida, no sentido de suprir as necessidades especiais oriundas da síndrome.

Ao longo do desenvolvimento do filho, foi possível constatar que o diagnóstico deixa de ser o protagonista, perdendo o papel central na medida em que o vínculo afetivo e a convivência diária evidenciam características singulares do filho. Assim, ele passa a ser percebido pelo pai como uma pessoa especial e única, produto e produtor de uma relação afetiva. Na fase adulta do filho, a síndrome já ocupa um lugar subjacente, e não mais preponderante como na fase inicial do diagnóstico.
A partir deste estudo, destaca-se a capacidade dos pais de investirem na relação pai-filho, tendo se mostrado como figuras fundamentais em suas vidas. A partir daí, refere-se à importância de que os pais, além das pessoas com síndrome de Down ou suas mães, sejam também incluídos nas ações de apoio à família e à pessoa com síndrome de Down. Os pais, assim como as mães, precisam ser considerados como pessoas que participam ativamente da vida dos filhos com síndrome de Down, que podem se sentir sobrecarregados na tarefa diária de cuidado ao filho e frente às demandas emocionais advindas deste cuidado.

Em relação à informação sobre a síndrome, destaca-se que no Brasil, no compasso de políticas de proteção e promoção do desenvolvimento da pessoa com deficiência, as mídias televisiva e virtual têm abordado o assunto de forma positiva. Programas de auditório e telenovelas apresentam as potencialidades das pessoas com síndrome de Down, o que favorece o conhecimento desta realidade para uma grande parte da população. Diante disso, é possível que os jovens pais de bebês não se sintam tão carentes de informações, como os participantes deste estudo. Para se confirmar a ideia referida, é essencial o investimento em pesquisas sobre o tema que tenham um caráter comparativo.

Como limitação do estudo, indica-se o fato de os dados referentes ao momento diagnóstico terem sido coletados de forma retrospectiva, referindo-se a uma situação vivida pelos pais há duas ou três décadas. De qualquer forma, pode-se supor que a intensidade emocional associada às vivências da época tenha conferido uma capacidade de registro e de memorização significativa associada às mesmas. Desta forma, foi possível para os pais acessarem facilmente tais recordações. Contudo, recomenda-se a elaboração de estudos com delineamento longitudinal a fim de sanar tal limitação.

Considerando também que os filhos adultos deste estudo foram diagnosticados há mais de duas décadas, sugere-se novos estudos sobre como os pais atualmente estão recebendo a informação do diagnóstico. É necessário detectar avanços na capacidade profissional da equipe de saúde em fornecer o diagnóstico, de forma a apresentar aos pais, também as capacidades de uma criança com síndrome de Down e não apenas as limitações associadas. 


\section{Referências}

Albuquerque, S., Pereira, M., Fonseca, A., \& Canavarro, M. C. (2012). Impacto familiar e ajustamento de pais de crianças com diagnóstico de anomalia congênita: Influência dos determinantes da criança. Revista de Psiquiatria Clínica, 39(4), 136-141. https://doi.org/10.1590/S0101-60832012000400004

Almeida, P. (2013). Vivendo com síndrome de Down. Rio de Janeiro, RJ: Movimento Down. Recuperado de http://www.movimentodown.org.br/2013/01/vivendo-com-sindrome-de-down/

Alonso, M. A. V. (2011). Discapacidad intelectual: Definición, clasificación y sistemas de apoyo (11a ed.). Madrid: Alianza.

Amiralian, M. L. T. M. (2014). O pai nos dias de hoje e as consequências para o desenvolvimento. In Rosa, C. D. (Org.), E o pai? Uma abordagem winnicottiana. São Paulo, SP: DWW.

Anônimo. (2016). Cidadania e justiça: Estatuto da pessoa com deficiência entra em vigor. Portal Brasil. Recuperado de http://www.brasil.gov.br/cidadania-e-justica/2016/01/estatuto-da-pessoa-com-deficiencia-entra-em-vigor

Balancho, L. S. F. (2004). Ser pai: Transformações intergeracionais na paternidade. Análise Psicológica, 2(22), 377-386.

Bardin, L. (2010). Análise de conteúdo (L. A. Rego, \& A. Pinheiro, Trads.). Lisboa: 70. (Obra original publicada em 1977).

Bastos, O. M., \& Deslandes, S. F. (2009). Adolescer com deficiência mental: A ótica dos pais. Ciência \& Saúde Coletiva, 14(1), 79-87. https://doi.org/10.1590/S1413-81232009000100013

Bentley, G. E., Zvonkovic, A., McCarty, M., \& Springer, N. (2015). Down syndrome and fathering: An exploration of Ambiguous Loss. Fathering, Spring, 13(1), 1-17. https://doi.org/10.3149/fth.1301.1

Bossardi, C. N., \& Vieira, M. L. (2010). Cuidado paterno e desenvolvimento infantile. Revista de Ciências Humanas, 44(1), 205-221. https://doi.org/10.5007/2178-4582.2010v44n1p205

Bueno, R. K., \& Vieira, M. L. (2014). Análise de estudos brasileiros sobre o pai e o desenvolvimento infantil. Psicologia Argumento, 32(76), 151-159. https:// doi.org/10.7213/psicol.argum.32.076.AO10

Casarin, S. (2003). Aspectos psicológicos na síndrome de Down. In J. S. Schwartzman (Org.), Síndrome de Down (pp. 263-285). São Paulo, SP: Memnon.

Castro, A. S. A., \& Pimentel, S. C. (2009). Atendimento educacional específico: Síndrome de Down, desafios e perspectivas na inclusão escolar. In F. Díaz, M. Diaz, N. Galvão, T. Miranda (Orgs), Educação inclusiva, deficiência e contexto social: Questões contemporâneas (pp. 303-312). Salvador, BA: Edufba. Recuperado de http://books. scielo.org/id/rp6gk/pdf/diaz-9788523209285-28.pdf

Cia, F., Williams, L. C. A., \& Aiello, A. L. R. (2005). Influências paternas no desenvolvimento infantil: Revisão de literatura: Relacionamento pai-filho. Psicologia Escolar e Educacional, 9(2), 225-233. https:/ /doi.org/10.1590/S141385572005000200005

Cunha, A. M. F. V., Blascovi-Assis, S. M., \& Fiamenghi Junior, G. A. (2010). Impacto da notícia da síndrome de Down para os pais: Histórias de vida. Ciência \& Saúde Coletiva, 15(2), 444-451. https://doi.org/10.1590/S141381232010000200021

Cunningham, C. (2008). Síndrome de Down: Uma introdução para pais e cuidadores (3a ed., R. C. Costa, Trad.). Porto Alegre, RS: Artmed.

Darke, P. R., \& Goldberg, S. (1994). Father-infant interaction and parent stress with healthyand medically compromised infants. Infant Behaviorand Development, 17(1), 3-14. https://doi.org/10.1016/0163-6383(94)90017-5

Espigares, A. M. (2012). A educação das pessoas com síndrome de Down. In M. A. L. Royo, \& N. L. Urquízar (Orgs.), Bases psicodiagnósticas da educação especial (R. Rosenbusch, Trad.). Petrópolis, RJ: Vozes.

Ethier, O. F. (1999). Comparing mother's and father's expectations for their young children with and without special needs (Dissertação de mestrado). Departament of Educational Psychology and Leadership Studies, University of Victory, Victoria, Canadá. 
Fainblum, A. (2008). Clínica de la Discapacidad. In A. Fainblum, Discapacidad, una perspectiva clínica desde el psicoanálisis (2a ed., pp.17-25). Buenos Aires: La Nave de Los Locos.

Falceto, O. G., Fernandes, C. L., \& Kerber, S. R. (2012). Alerta sobre a depressão pós-parto paterna. Revista Brasileira de Ginecologia e Obstretícia, 34(7), 293-295.

Féres-Carneiro, T., Ziviani, C., Magalhães, A. S., \& Ponciano, E. L. T. (2013). Ser pai (mãe), ser filho(a): A resolução de conflitos em famílias contemporâneas casadas. In T. Féres-Carneiro (Org.), Casal e família: Transmissão, conflito e violência. São Paulo, SP: Casa do Psicólogo.

Glat, R., \& Duque, M. A. T. (2003). Convivendo com filhos especiais: O olhar paterno (7a ed.). Rio de Janeiro, RJ: Sete Letras.

Goetz, E. R., \& Vieira, M. L. (2013). Pai real, pai ideal: O papel paterno no desenvolvimento infantil. Curitiba, PR: Juruá.

Gutfreind, C. (2010). Narrar ser mãe, ser pai \& outros ensaios sobre a parentalidade. Rio de Janeiro, RJ: Difel.

Henn, C. G., \& Piccinini, A. C. (2010). A experiência da paternidade e o envolvimento paterno no contexto da síndrome de Down. Psicologia: Teoria e Pesquisa, 26(4), 623-631. https://doi.org/10.1590/S010237722010000400006

Iaconelli, V. (2011). Depressão pós-parto masculina. São Paulo, SP: Instituto Brasileiro de Psicologia Perinatal Gerar. Recuperado de http://www.institutogerar.com.br/artigos/23_ARTIGO_DEPRESS\%C3\%83O\%20POS\%20 PARTO\%20MASCULINA.pdf

Klaus, M. H., Kennell, J. H., \& Klaus, H. (2000). Vínculo: Construindo as bases para um apego seguro e para a independência (M. R. Hofmeister, Trad.). Porto Alegre, RS: Artes Médicas Sul.

Laville, C., \& Dionne, J. (1999). Em busca de informações. In C. Laville, \& J. Dionne, A construção do saber: Manual de metodologia da pesquisa em ciências humanas (cap. 7, pp. 165-196). Porto Alegre, RS: Artes Médicas.

Matos, H. S., Andrade, T. S., Mello, I. T., \& Sales, Z. N. (2006). Concepções de mães em relação a filhos portadores da síndrome de Down. Revista Saúde.Com, 2(1), 59-68.

Minayo, M. C. S. (2014). O desafio do conhecimento-pesquisa qualitativa em saúde (11a ed.). São Paulo, SP: Hucitec.

Ministério da Saúde. (2013). Diretrizes de atenção à pessoa com síndrome de Down. Brasília, DF: o autor.

Pereira, R. C. (2003). Pai, por que me abandonaste? In G. C. Groeninga, Família: um caleidoscópio de relações. In G. C. Groeninga, \& R. C. Pereira (Coords.), Direito de família e psicanálise: Rumo a uma nova epistemologia. Rio de Janeiro, RJ: Imago.

Pereira-Silva, N. L., \& Almeida, B. R. (2014). Reações, sentimentos e expectativas de famílias de pessoas com necessidades educacionais especiais. Psicologia Argumento, 32(Supl. 2), 111-122.

Pereira-Silva, N. L., \& Dessen, M. A. (2003). Crianças com síndrome de Down e suas interações familiares. Psicologia: Reflexão e Crítica, 16(3), 503-514. https://doi.org/10.1590/S0102-79722003000300009

Sabadini, A. A. Z. P., Sampaio, M. I. C., \& Koller, S. H. (Org.). (2009). Publicar em psicologia um enfoque para a revista científica. São Paulo, SP: Associação Brasileira de Editores Científicos de Psicologia.

Silva, E. H. P., Girão, E. R. C., \& Cunha, A. C. B. (2016). Enfrentamento do pai frente à malformação congênita do filho antes e depois do nascimento. Universidade Federal do Rio de Janeiro, Rio de Janeiro, Brasil.

Souza, A. B., \& Fiamenghi, G.A., Jr. (2011). A relação entre pai e filho com síndrome de Down: Uma revisão de literatura. Cadernos de Pós-Graduação em Distúrbios do Desenvolvimento, 11(1), 23-27.

Staudt, A. C. P., \& Wagner, A. (2008). Paternidade em tempos de mudança. Psicologia: Teoria e Prática, $10(1), 174-185$.

Sunelaitis C. R., Arruda D. C., \& Marcom S. S. (2007). A repercussão de um diagnóstico de síndrome de Down no cotidiano familiar: Perspectiva da mãe. Acta Paul Enfermagem, 20(3), 264-271. https://doi.org/10.1590/S010321002007000300004.

Travassos-Rodriguez, F. (2007). Síndrome de Down: Da estimulação precoce do bebê ao acolhimento precoce da família (Tese de doutorado). Pontifícia Universidade Católica do Rio de Janeiro, Rio de Janeiro, RJ, Brasil. 


\section{Marilise Ferreira}

Psicóloga. Educadora Especial. Mestre em Psicologia pela Universidade Federal de Santa Maria (UFSM), Santa Maria - RS. Brasil.

E-mail: mary_f100@hotmail.com

(iD) http://orcid.org/0000-0003-3720-5096

Caroline Rubin Rossato Pereira

Psicóloga. Doutora em Psicologia pela Universidade Federal do Rio Grande do Sul (UFRGS), Porto Alegre - RS. Brasil. Especialista em Psicologia Clínica com ênfase em Terapia Familiar e de Casal pelo Instituto da Família de Porto Alegre (INFAPA), Porto Alegre - RS. Brasil. Docente do Departamento de Psicologia e Programa de PósGraduação em Psicologia da Universidade Federal de Santa Maria (UFSM), Santa Maria - RS. Brasil.

E-mail: carolinerrp@gmail.com

(iD) http://orcid.org/0000-0001-9861-8391

\section{Luciane Najar Smeha}

Psicóloga. Doutora em Psicologia pela Pontifícia Universidade Católica (PUC-RS), Porto Alegre-RS. Brasil. Docente no Curso de Psicologia e Mestrado em Saúde Materno-Infantil do Centro Universitário Franciscano (UNIFRA), Santa Maria - RS. Brasil.

E-mail: lucianenajar@yahoo.com.br

(iD) http://orcid.org/0000-0002-3068-3776

\section{Patrícia Paraboni}

Psicóloga. Pós-Doutoranda e Professora Colaboradora do Programa de Pós-Graduação em Psicologia da Universidade Federal de Santa Maria (UFSM), Santa Maria - RS. Brasil. Bolsista CAPES.

E-mail: pparaboni@yahoo.com.br

(iD http://orcid.org/0000-0003-2413-150X

\section{Andréia Sorensen Weber}

Psicóloga. Mestranda do Programa de Pós-Graduação em Psicologia da Universidade Federal de Santa Maria (UFSM), Santa Maria - RS. Brasil.

E-mail: andreia.sorensen@hotmail.com

(D) http://orcid.org/0000-0002-8147-2207

Endereço para envio de correspondência:

Rua Euclides da Cunha, 620. CEP: 97090-000.

Itararé, Santa Maria - RS. Brasil. CEP 97090-000

Recebido 13/06/2017

Reformulado 12/08/2019

Aceito 23/09/2019

Received 06/13/2017

Reformulated $08 / 12 / 2019$

Approved 09/23/2019 
Psicologia: Ciência e Profissão 2019 v. 39, e181365, 1-14.

Recibido 13/06/2017

Reformulado 12/08/2019

Aceptado 23/09/2019

Como citar: Ferreira, M., Pereira, C. R. R., Smeha, L. N., Paraboni, P., \&Weber, A. S. (2019). Repercussões do diagnóstico de síndrome de Down na perspectiva paterna. Psicologia: Ciência e Profissão, 39, 1-14. https://doi.org/10.1590/1982-3703003181365

How to cite: Ferreira, M., Pereira, C. R. R., Smeha, L. N., Paraboni, P., \&Weber, A. S. (2019). Repercussions of Down syndrome diagnosis from the paternal perspective. Psicologia: Ciência e Profissão, 39, 1-14.

https://doi.org/10.1590/1982-3703003181365

Cómo citar: Ferreira, M., Pereira, C. R. R., Smeha, L. N., Paraboni, P., \&Weber, A. S. (2019). Repercusiones del diagnóstico del síndrome de Down desde la perspectiva paterna. Psicologia: Ciência e Profissão, 39, 1-14. https://doi.org/10.1590/1982-3703003181365 